\title{
The Inhibition of the Growth of Clostridium welchii by Lipids Isolated from the Contents of the Small Intestine of the Pig
}

\author{
By R. FULLER AND J. H. MOORE \\ National Institute for Research in Dairying, Shinfield, Reading, Berkshire
}

(Accepted for publication 1 August 1966)

\begin{abstract}
SUMMARY
The growth of Clostridium welchii type A NCTC 8246 was inhibited by the contents of the small intestine of pigs from which food had been withheld for $24 \mathrm{hr}$; no inhibitory activity was observed by the contents of the stomach, caecum and large intestine. Inhibitory activity was absent from the contents of the small intestine during the early stages of digestion but first appeared about $6 \mathrm{hr}$ after the pigs had been given food. This indicated that under normal feeding practice there were periods during each day when the contents of the small intestine would be inhibitory for $C$. welchii. The inhibitory activity was in the lipid fraction of the intestinal contents. Fractionation of the intestinal lipids showed that the inhibitory substances were linoleic and arachidonic acids, lysolecithin and an unidentified phospholipid. The poly-unsaturated fatty acids and lysolecithin appeared to be derived mainly from the action of pancreatic phospholipase A on biliary lecithin in the lumen of the small intestine. The possibility that these inhibitory lipids control to some extent the numbers of $C$. welchii in the alimentary tract of the pig is discussed.
\end{abstract}

\section{INTRODUCTION}

During an investigation of the microflora of the alimentary tract of the pig it was observed that the contents of the small intestine inhibited the growth of certain micro-organisms. A study of the factors responsible for this inhibition is now reported.

\section{METHODS}

Pigs. The animals used in this work were of the herd of Large Whites maintained at the National Institute for Research in Dairying. The pigs were weaned at 8 weeks and were then given a commercial pig diet until they were sent at the age of 4-7 months to the local slaughterhouse. As is normal practice, food was withheld from certain of the animals for $24 \mathrm{hr}$ before they were killed. Other animals were killed at 4, 6, 15 or $21 \mathrm{hr}$ after they had been given food. In all, some thirty pigs were examined.

Collection and treatment of material. The gastro-intestinal tracts, gall bladders and pancreatic tissues were collected at the slaughterhouse within $20 \mathrm{~min}$. of death. The gastro-intestinal tract was divided into the stomach, small intestine, caecum and large intestine; as rapidly as possible thereafter the contents were removed from each section of the tract. To remove gross food residues, the samples of contents were centrifuged at $1250 \mathrm{~g}$ for $30 \mathrm{~min}$. The supernatant fluid was removed and the dry 
matter content of each sample determined so that the concentration of the various components in the fluid phase of the gastro-intestinal contents could subsequently be calculated. The samples of intestinal fluid were either stored at $-20^{\circ}$ or freeze-dried and then stored at $-20^{\circ}$ until required for the determination of antibacterial activity or for chemical investigation. Samples of the small intestine wall, obtained from the upper, middle and lower regions, were washed free from contents with $0.85 \%(\mathrm{w} / \mathrm{v})$ $\mathrm{NaCl}$ solution. Portions of each of the three sections were pooled and homogenized in $0.85 \%(\mathrm{w} / \mathrm{v}) \mathrm{NaCl}$ solution. The homogenate was centrifuged at $1250 \mathrm{~g}$ for $30 \mathrm{~min}$. and the supernatant fluid removed and stored at $-20^{\circ}$. Bile was removed from the gall bladders and was stored at $-20^{\circ}$ until required. Acetone-dried powders of the pancreatic tissues were prepared as described by Laws \& Moore (1963).

Sterilization of material. Initially, intestinal contents and extracts of intestinal tissues were sterilized by Seitz filtration but, after it had been shown that the inhibitory factors were heat stable, material was sterilized in an autoclave by allowing a pressure of 10 pounds $/$ inch $^{2}\left(115^{\circ}\right)$ to develop and then immediately removing the source of heat. In the case of lipid fractions, the chloroform treatment (see later) was sufficient to sterilize the sample.

Organisms tested. The microbial spectrum of inhibitory activity was determined as follows. A well cut in the centre of a yeast glucose agar plate was filled with contents of the small intestine and the contents were allowed to diffuse in the cold for $24 \mathrm{hr}$. The test organism was streaked up to the edge of the well, the plates incubated at $37^{\circ}$ for $24 \mathrm{hr}$ and then examined for inhibition. The organisms tested were Clostridium welchii type A, NCTC 8246; Salmonella paratyphi B, NCTC 5705; S. cholerae suis, NCTC 5735, and three strains of haemolytic Escherichia coli (isolated from cases of oedema disease by Mr W. J. Sojka, Central Veterinary Laboratories, Weybridge). Other organisms tes ،c were $E$. coli I, $E$. coli III; Streptococcus equinus, $S$. faecalis, S. liquefaciens, $S$. durans, $S$. faecium, $S$. bovis, two unclassified streptococci; Lactobacillus salivarius, L. acidophilus, L. brevis, L. fermenti, L. cellobiosus and L. plantarum all isolated from the alimentary tracts of normal pigs as described by Fuller et al. (1960).

Test for inhibitory activity. Preliminary tests on a number of different organisms showed that Clostridium welchii NCTC 8246 and two others were the most sensitive to the inhibitory agent; $C$. welchii NCTC 8246 was adopted as the test organism. Cultures were grown in glucose Lemco broth $(\%, w / v$ : Evans peptone, 1 ; Lab. Lemco, 1 ; $\mathrm{NaCl}, 0 \cdot 5$; glucose, 1$)$. Spore crops were produced by the method of Ellner (1956) and the remaining vegetative organisms killed by heating at $80^{\circ}$ for $10 \mathrm{~min}$.

To $0.9 \mathrm{ml}$. of the test material was added $0.1 \mathrm{ml}$. of an overnight culture of Clostridium welchii NCTC 8246 in glucose Lemco broth for vegetative organisms or in the medium of Ellner (1956) for spores. The number of viable vegetative forms added was between $5 \times 10^{6}$ and $5 \times 10^{7}$; the number of viable spores present in the spore inoculum was about $10^{4}$. After $5 \mathrm{hr}$ contact in an anaerobic atmosphere of $95 \%(\mathrm{v} / \mathrm{v}) \mathrm{H}_{2}+5 \%(\mathrm{v} / \mathrm{v})$ $\mathrm{CO}_{2}$ colony counts were made on nutrient agar containing $5 \%(\mathrm{v} / \mathrm{v})$ sheep blood and incubated anaerobically for $24 \mathrm{hr}$ at $37^{\circ}$.

For the titration of inhibitory activity, dilutions were made in $0.1 \mathrm{M}$-phosphate buffer ( $\mathrm{pH} \mathrm{6.5)} \mathrm{containing} 0.1 \%(\mathrm{w} / \mathrm{v})$ Tween 80 (polyoxyethylene sorbitan monooleate; obtained from Honeywill \& Stein Ltd., London). The Tween 80 was purified by the method of Bier (1955) and was included to emulsify the lipid fractions in the test solutions. Stable emulsions of the various lipid fractions were prepared as follows. 
A known amount of lipid dissolved in chloroform was placed in a glass-stoppered tube and the solvent removed under reduced pressure at room temperature by means of a rotary film evaporator attached to a supply of nitrogen. The requisite volume of a solution of Tween 80 in chloroform was then added and the solvent was again removed. When all traces of chloroform had disappeared the requisite volume of $0 \cdot 1 \mathrm{M}$-phosphate buffer was added and the tubes were shaken vigorously. Solvent controls were prepared similarly. It was established that there was no inhibition due to the presence of Tween 80 . To assess the minimum inhibitory concentrations of the various lipid fractions, the lowest concentration at which each fraction completely sterilized the inoculum was determined. In Table 1 the results are expressed as the $\%$ of the inoculum killed when the undiluted intestinal material was tested. Unless otherwise stated, all fractions separated from the intestinal contents were reconstituted and tested at the concentration at which they occurred in the fluid phase of the intestinal contents.

Extraction of lipids The lipids were extracted from the freeze-dried contents and cultures of $C$. welchii NCTC 8246 by a method similar to that described by Folch, Lees $\&$ Stanley (1957). The lipids were extracted from pig bile by a procedure adapted from that devised for plasma lipids by Nelson \& Freeman (1959). The total lipid contents of the purified lipid extracts were determined gravimetrically.

Chromatography on columns of silicic acid. Total phospholipids were separated from the non-phospholipids by fractionating portions of the lipid extracts on $3 \mathrm{~g}$. columns of silicic acid (100 mesh: A.R.; Mallinckrodt Chemical Works, New York). As described by Moore \& Doran (1962) the non-phospholipids were eluted from the columns with chloroform and the total phospholipids with chloroform + methanol $(1+4$, by vol.) and then methanol. The unesterified fatty acids were separated from the other non-phospholipids (cholesterol, cholesterol esters, glycerides) by chromatography on columns of Florisil (Koch-Light Laboratories Ltd., Colnbrook, Buckinghamshire) according to the method of Carroll (1961). The individual phospholipids were fractionated on $5 \mathrm{~g}$. columns of silicic acid. The columns were prepared by the method of Marinetti, Erbland \& Kochen (1957). The individual phospholipids were then eluted with chloroform + methanol mixtures by the procedure of Hanahan, Dittmer \& Warashina (1957) as modified by Moore \& Doran (1961).

Chromatography on thin-layer plates of silica gel and on filter paper impregnated with silicic acid. The individual phospholipids were also separated by fractionation on thin-layer chromatoplates of silica gel (Camag A.G., Muttenz, Switzerland) with a solvent system of chloroform + methanol + acetic acid + water $(25+15+4+2$, by vol. $)$ as described by Skipski, Peterson \& Barclay (1964). After development the chromatograms were sprayed with a solution of dichlorofluorescein $(0.1 \%, \mathrm{w} / \mathrm{v})$ in methanol + water $(95+5$, by vol.) and the positions of the various phospholipid bands located by viewing the plates under ultraviolet radiation. The various phospholipid fractions were eluted from the bands of silica gel by the procedure of Skipski et al. (1964). As additional aids in the identification of the various compounds, the phospholipids were chromatographed by the technique of Marinetti (1963) on filter paper impregnated with silicic acid and by the technique of Mangold (1961) on thin-layer plates of silica gel G (E. Merck A.G., Darmstadt, Germany) + ammonium sulphate $(90+10$, by weight) with a solvent system of chloroform + methanol + water $(65+2+5$, by vol. $)$. Chromatography on thin-layer plates of silica gel G with a solvent system of chloro- 
form + methanol $+14 \mathrm{~N}$-ammonia $(65+25+4$, by vol.) was also used to establish the identity of certain of the phospholipids (Horrocks, 1963).

Fatty acid analysis. The fatty acids present in the various phospholipid and unesterified fatty acid fractions were converted to the corresponding methyl esters by the trans-esterification procedure of Stoffel, Chu \& Ahrens (1959). The methyl esters were analysed by gas-liquid chromatography on both non-polar and polar columns (Moore \& Williams, 1963, 1964). The non-polar (APL) columns consisted of $10 \%(w / w)$ Apiezon L grease on 100-120 mesh Celite and the polar (PEGA) columns consisted of $10 \%(\mathrm{w} / \mathrm{w})$ polyethylene glycol adipate also on 100-120 mesh celite. Identification of the methyl esters of the fatty acids was made by comparison of their retention times on the two types of columns with those of known standard methyl esters and by plotting the logarithms of their retention times relative to methyl palmitate on PEGA columns against the logarithms of their retention times relative to methyl palmitate on APL columns (James, 1959). A check on the number of double bonds in each fatty acid was made by fractionating certain of the samples of methyl esters on thin-layer plates of silica gel $G+$ silver nitrate $(95+5$, by weight) with a solvent system of light petroleum (b.p. $\left.40-60^{\circ}\right)+$ diethyl ether $(85+5$, by vol.). This technique (Morris, 1962) separated the methyl esters into saturated, mono-, di-, tri- and tetra-enoic acid esters. The separated zones were scraped from the plates and the methyl esters were eluted from the silica gel $\mathrm{G}+$ silver nitrate with hexane + diethyl ether $(50+50$, by vol.). The resulting methyl ester fractions were then analysed by gas-liquid chromatography. Thus, by these procedures, the number of carbon atoms and the number of double bonds in each fatty acid could be established.

Reference compounds. From egg yolk, phosphatidyl choline was prepared by the technique of Saunders (1957) and phosphatidyl ethanolamine by the technique of Rhodes \& Lea (1957). The method of Saunders (1957) was also used to prepare pure lecithin from pig bile. Lysophosphatidyl choline and lysophosphatidyl ethanolamine were obtained after the corresponding pure diacyl compounds had been hydrolysed with the phospholipase A of snake (Crotalus adamenteus) venom. To prepare phosphatidic acid a sample of pure phosphatidyl choline was hydrolysed with the phospholipase D of cabbage by the method of Kates (1954). Phospholipase A and D and sphingomyelin were obtained from Koch-Light Laboratories Ltd. Diphosphatidyl glycerol (cardiolipin) was prepared from pig heart by the technique of MacFarlane (1961). Pure fatty acids and their methyl esters were obtained from Calbiochem Inc., New York.

Hydrolysis of phospholipids with phospholipase A. Phospholipase A solutions were prepared from snake venom by the method of Long \& Penny (1957) or from an acetone-dried powder of pig pancreas by the method of Magee, Gallai-Hatchard, Sanders \& Thompson (1962). The conditions of hydrolysis of lecithin and phosphatidyl ethanolamine were the same as those described in detail by Moore \& Williams $(1964,1965)$. The reaction products, i.e. unesterified fatty acids and lyso-compounds, were separated on columns of silicic acid as described by Moore \& Williams (1964).

Chemical analysis. Unesterified fatty acids were determined by the microtitration procedure of Albrink (1959) and lipid phosphorus was determined by the methods of Allen (1940) and Chen, Torribara \& Warner (1956). 


\section{RESULTS}

The location of inhibitory activity and the variation in the inhibitory activity of the contents of the pig small intestine with time after feeding

Inhibitory activity (this refers throughout to tests against Clostridium welchii type A, NCTC 8246) was tested for in the contents of the stomach, small intestine, caecum and colon. The activities of bile and of saline extracts of the wall of the small intestine were also examined. Significant inhibitory activity was found only in the contents of the small intestine.

It is commercial practice to withhold food from pigs on the day of slaughter so that animals may have been fasted for $20-24 \mathrm{hr}$ when they are killed. Inhibitory activity was found in the contents of all of the small intestines obtained from twenty pigs that had been sent to the slaughterhouse in this way. However, it was important to investigate to what extent the inhibitory activity of the contents of the small i ntestine varied as the period of time after feeding was decreased. The results of such an investigation are shown in Table 1, from which it can be seen that no activity was detected in the contents of the small intestine of pigs that were killed $4 \mathrm{hr}$ after they had been fed. Appreciable inhibitory activity was detected in the contents of the small intestines of animals killed $6 \mathrm{hr}$ or more after they had been fed. The pigs in the Shinfield herd are given food twice a day and the periods between feeds are $7 \mathrm{hr}$ during the day and $17 \mathrm{hr}$ during the night. Thus it would appear that there are periods of about 1 and $11 \mathrm{hr}$ in every $24 \mathrm{hr}$ when the contents of the small intestine might be inhibitory for Clostridium welchii.

Table 1. Variation in inhibitory activity against Clostridium welchii type A, NCTC 8246, of the contents of the pig small intestine with time after feeding

\begin{tabular}{|c|c|c|}
\hline $\begin{array}{l}\text { Time after } \\
\text { feeding } \\
\text { (hr) }\end{array}$ & Pig no. & $\begin{array}{c}\text { Proportion of } \\
\text { Clostridium welchii } \\
\text { inoculum killed } \\
(\%)\end{array}$ \\
\hline 4 & $\left\{\begin{array}{l}1 \\
2 \\
3\end{array}\right.$ & $\begin{array}{r}0.0 \\
0.0 \\
26.0\end{array}$ \\
\hline 6 & $\left\{\begin{array}{l}4 \\
5 \\
6\end{array}\right.$ & $\begin{array}{l}99 \cdot 9 \\
99 \cdot 9 \\
99 \cdot 9\end{array}$ \\
\hline 15 & $\left\{\begin{array}{l}7 \\
8 \\
9\end{array}\right.$ & $\begin{array}{r}93.9 \\
99 \cdot 9 \\
100 \cdot 0\end{array}$ \\
\hline 24 & $\left\{\begin{array}{l}10 \\
11 \\
12\end{array}\right.$ & $\begin{array}{l}100 \cdot 0 \\
100 \cdot 0 \\
100 \cdot 0\end{array}$ \\
\hline
\end{tabular}

Microbial spectrum of inhibitory activity

None of the Gram-negative organisms tested was inhibited by the contents of the small intestine, neither were Streptococcus faecalis, S. durans, S. faecium, nor Lactobacillus plantarum. The other streptococci and lactobacilli showed slight inhibition on one of the two occasions when they were tested. C. welchii NCTC 8246 was markedly inhibited and was by far the most sensitive organism of those tested. 


\section{Preliminary observations on the nature of the inhibitory factor}

The inhibitory activity of the contents of the small intestine was destroyed when the contents were ashed but not when heated for $30 \mathrm{~min}$. at $56^{\circ}$ or for $10 \mathrm{~min}$. at $120^{\circ}$. Inhibitory activity was unaffected when the $\mathrm{pH}$ value of the intestinal contents was increased to $\mathrm{pH} 10$ but when decreased to $\mathrm{pH} 4$ the active substance appeared to be precipitated. The observation that the inhibitory factor was extracted from the intestinal contents with diethyl ether suggested that the factor was present in the lipid fraction of the intestinal contents. The fact that the growth of Clostridium welchii was not inhibited by pig bile indicated that the inhibitory activity of the intestinal contents could not be attributed to the bile acids that would be present in them. Nevertheless, tests were made with pure bile acid salts, but solutions of sodium glycocholate $(2 \%, \mathrm{w} / \mathrm{v})$ and sodium taurocholate $(8 \%, \mathrm{w} / \mathrm{v})$ possessed no inhibitory activity.

The colony counts made at the end of the period of contact involved dilution beyond the point at which the inhibitory agent was active. In spite of this, organisms still present at this dilution did not grow when plated out on nutrient agar containing $5 \%(\mathrm{v} / \mathrm{v})$ sheep blood. For this reason the substance was considered to be bactericidal.

\section{Fractionation of the intestinal contents}

During the investigation various samples of intestinal contents were fractionated and the inhibitory activities of the various fractions were determined. The fractionation of a sample of intestinal contents with high inhibitory activity is now described as an example of the type of result obtained. The pooled sample (no. 1) of intestinal contents used in this fractionation was obtained from four pigs from which food had been withheld for $24 \mathrm{hr}$ before slaughter.

Freeze-dried material (30 g.), equivalent to $360 \mathrm{ml}$. intestinal fluid, was refluxed for $2 \mathrm{hr}$ with $750 \mathrm{ml}$. chloroform, $750 \mathrm{ml}$. methanol and $120 \mathrm{ml}$. water. After the addition of a further $750 \mathrm{ml}$. chloroform the mixture was filtered through a funnel fitted with a sintered-glass plate. No antibacterial activity was found in the insoluble residue. To purify the crude lipid extract, $500 \mathrm{ml}$. water were added to the filtrate and the resulting mixture shaken and then allowed to stand at room temperature until separation between the lower chloroform layer and the upper aqueous methanol layer was complete. The purified lipid contained in the chloroform layer possessed inhibitory activity; the material in the aqueous methanol solution did not. A portion (59 mg.) of the purified lipid dissolved in a small volume of chloroform was placed on a $3 \mathrm{~g}$. column of silicic acid. The non-phospholipids were eluted with $300 \mathrm{ml}$. chloroform and the phospholipids with $200 \mathrm{ml}$. chloroform + methanol $(1+4$, by vol.) followed by $100 \mathrm{ml}$. methanol. Both the non-phospholipid and phospholipid fractions contained inhibitory factors. Thin-layer chromatography showed the presence of cholesterol, cholesterol esters, triglycerides, diglycerides, monoglycerides and unesterified fatty acids in the non-phospholipid fraction. The non-phospholipid fraction was separated into unesterified fatty acids and neutral lipids by chromatography on a $5 \mathrm{~g}$. column of Florisil. Antibacterial activity was found in the unesterified fatty acid fraction but none was detected in the neutral lipids (cholesterol, cholesterol esters, glycerides). The neutral lipid fraction was not investigated any further. The various steps in the fractionation procedure up to this stage are shown in Fig. 1, which also 
shows the weights of the various fractions. Attention should be drawn to the relatively high concentration ( $12 \%$ ) of total lipid in the dry intestinal contents and the very high proportion $(55 \%)$ of unesterified fatty acids in the total intestinal lipids. The unesterified fatty acids were analysed by gas chromatography; the results are shown in Table 2, which also shows the calculated concentrations of each fatty acid in the

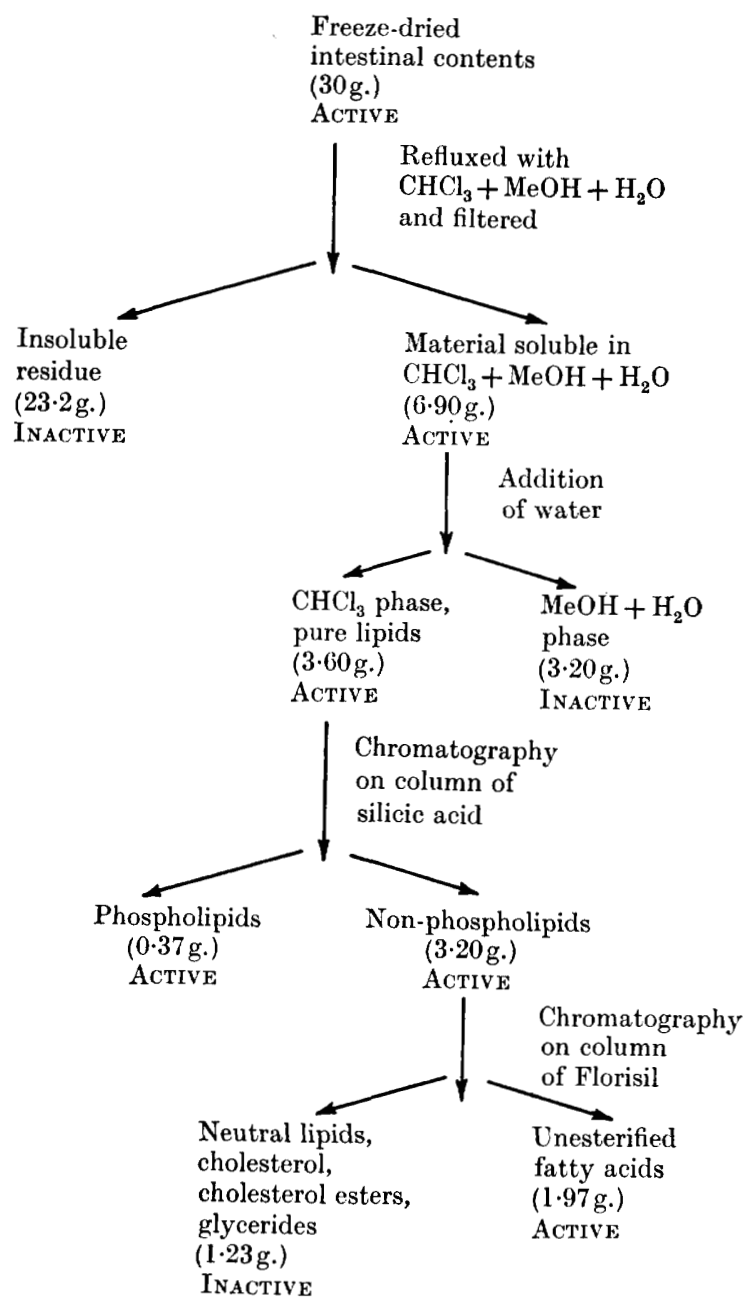

Fig. 1. Fractionation of pig intestinal contents sample no. 1. This sample was from a pool from four pigs having had food withheld for $24 \mathrm{hr}$ before slaughter.

intestinal fluid. Unsaturated fatty acids constituted about $65 \%$ of the total fatty acids and linoleic acid was the major fatty acid. In view of the small amounts of fatty acids used in gas chromatographic separations it was not possible to test the inhibitory activities of individual fatty acids that were actually isolated from the unesterified fatty acid fraction of the intestinal contents.

The intestinal phospholipids were analysed by quantitative thin-layer chromatography (Skipsky et al. 1964); the results, together with the calculated concentrations 
of individual phospholipids, are given in Table 3. Lysolecithin was the major phospholipid in the intestinal contents. Some doubt exists about the identity of one of the intestinal phospholipids, component A. When chromatographed on thin-layer plates of silica gel, either by the techniques of Skipski et al. (1964), Mangold (1961) or Horrocks (1963), component A moved with the solvent front. It also moved with the solvent front when chromatographed on filter paper impregnated with silicic acid

Table 2. Composition of the unesterified fatty acids present in the pig intestinal contents (sample no. 1)

Sample no. 1 was a pool of intestinal contents of 4 pigs from which food had been withheld for $24 \mathrm{hr}$ before slaughter.

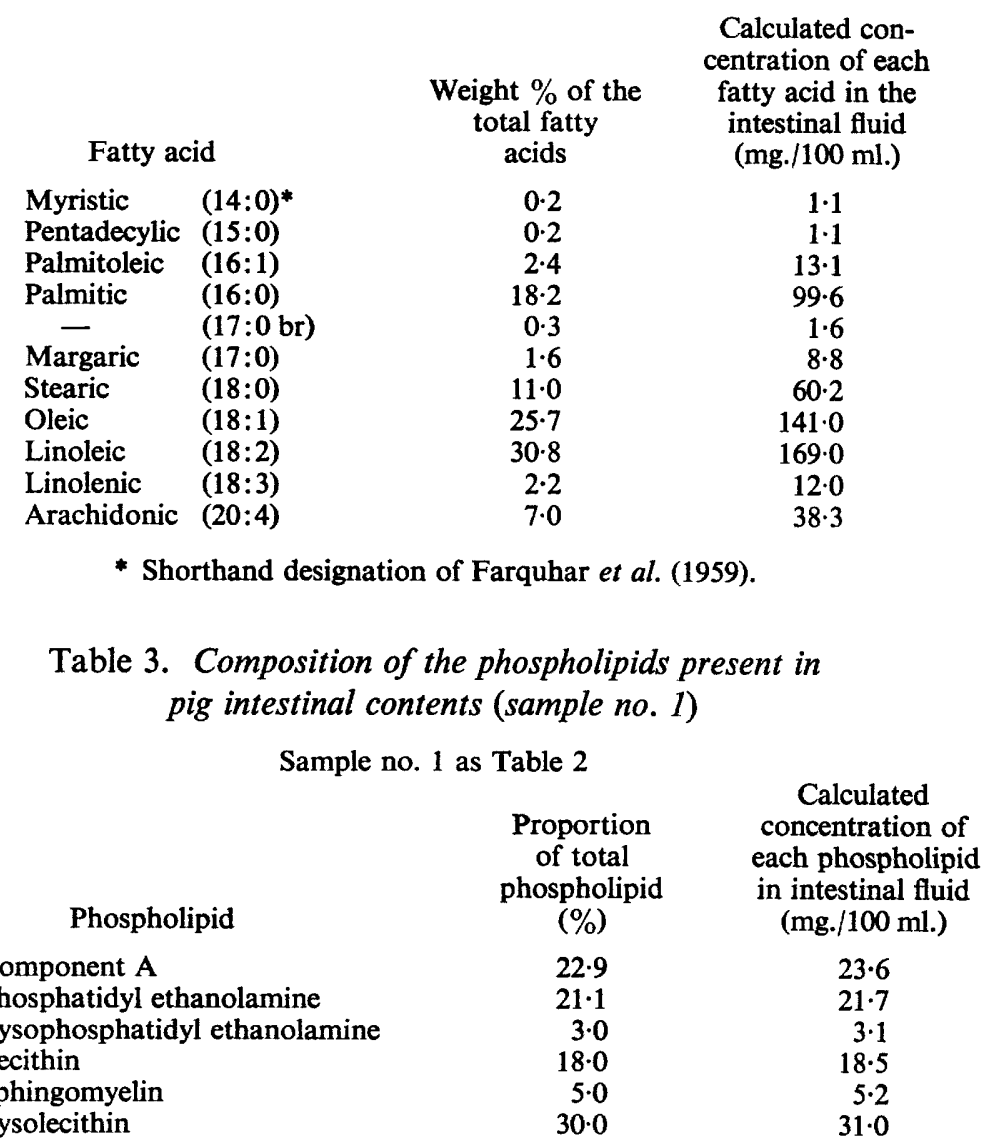

(Marinetti, 1963). Investigation by column chromatography revealed that component A was eluted from columns of silicic acid with chloroform + methanol $(95+5$, by vol.). Thus, the chromatographic behaviour of component A was similar to that described for diphosphatidyl glycerol by Skipski et al. (1964), Marinetti (1963) and MacFarlane (1961). A mixture of component A and diphosphatidyl glycerol prepared from pig heart was not separated by thin-layer chromatography. Thin-layer chromatography did not separate a mixture of component $A$ and phosphatidic acid. However, in spite 
of these similarities in chromatographic properties, evidence presented in a following section would seem to indicate that component $A$ was neither diphosphatidyl glycerol nor phosphatidic acid.

In order that the antibacterial activities of the various intestinal phospholipids could be tested, a portion of the mixed phospholipids containing about $750 \mu \mathrm{g}$. lipid phosphorus was fractionated on a $5 \mathrm{~g}$. column of silicic acid. Component A was eluted with chloroform + methanol $(95+5$, by vol.), phosphatidyl ethanolamine with chloroform + methanol $(80+20$, by vol.), lecithin with chloroform + methanol $(60+40$, by vol.) and lysolecithin with chloroform + methanol $(20+80$, by vol.). Examination of the four fractions by thin-layer chromatography revealed the presence of traces of lysophosphatidyl ethanolamine and sphingomyelin in the lecithin fraction. Traces of sphingomyelin were also observed in the lysolecithin fraction. Antibacterial activity was found in the fraction containing component $\mathrm{A}$ and in that containing lysolecithin and traces of sphingomyelin. Thin-layer chromatography (Mangold, 1961) of component A showed that this component was not contaminated with unesterified fatty acids. The lysolecithin fraction was rechromatographed on columns of silicic acid until traces of sphingomyelin were removed. Nevertheless, the inhibitory activity of the lysolecithin fraction was retained. It was concluded therefore that the antibacterial activity of the intestinal phospholipids was due to component $\mathrm{A}$ and to lysolecithin.

Table 4. Minimum inhibitory concentrations against Clostridium welchii NCTC 8246 of pure fatty acids and methyl esters in $0 \cdot 1 \mathrm{M}$-phosphate buffer ( $\mathrm{pH} 6.5$ or 7.5 ) containing $0 \cdot 1 \%(w / v)$ Tween 80

\begin{tabular}{|c|c|c|}
\hline \multirow[t]{2}{*}{ Fatty acid } & pH 6.5 & $\mathrm{pH} 7 \cdot 5$ \\
\hline & \multicolumn{2}{|c|}{$\begin{array}{l}\text { Minimal inhibitory concentratic } \\
(\mathrm{mg} . / 100 \mathrm{ml} .)\end{array}$} \\
\hline Caproic (6:0) & 1160 & 5810 \\
\hline Caprylic $(8: 0)$ & 721 & 3610 \\
\hline Capric $(10: 0)$ & 172 & 862 \\
\hline Lauric $(12: 0)$ & 1000 & 200 \\
\hline Myristic $(14: 0)$ & 2280 & 457 \\
\hline Palmitic (16:0) & $>2560$ & $>2560$ \\
\hline Stearic $(18: 0)$ & $>2850$ & $>2850$ \\
\hline Oleic $(18: 1)$ & 283 & 283 \\
\hline Erucic $(22: 1)$ & 339 & 339 \\
\hline Linoleic $(18: 2)$ & $5 \cdot 61$ & $5 \cdot 61$ \\
\hline Linolenic $(18: 3)$ & 27.9 & 27.9 \\
\hline Arachidonic $(20: 4)$ & 6.09 & 6.09 \\
\hline Methyl linoleate & 146 & 733 \\
\hline Methyl linolenate & 293 & 1460 \\
\hline
\end{tabular}

The inhibitory activities of various unesterified and esterified fatty acids

The inhibitory activities of the pure fatty acids and methyl esters listed in Table 4 were determined at concentrations between $10^{-1} \mathrm{M}$ and $10^{-5} \mathrm{M}$. Tests were carried out in $0.1 \mathrm{M}$-phosphate buffer containing $0.1 \%(\mathrm{w} / \mathrm{v})$ Tween 80 at $\mathrm{pH} 6.5$ and at $\mathrm{pH}$ 7.5. The minimum inhibitory concentration of each fatty acid is given in Table 4. An increase from $\mathrm{pH} 6.5$ to $\mathrm{pH} 7.5$ increased the minimum inhibitory concentrations of the short-chain acids (caproic, caprylic, capric) but decreased the minimum inhibitory 
concentrations of the two medium-chain fatty acids (lauric, myristic). At pH 6.5 and $7 \cdot 5$ palmitic and stearic acids were inactive at $10^{-1} \mathrm{M}$. (When present in concentrations greater than $10^{-1} \mathrm{M}$, palmitic and stearic acids formed unstable emulsions under the test conditions and were therefore not tested at concentrations greater than $10^{-1} \mathrm{M}$.) The minimum inhibitory concentrations of the unsaturated fatty acids were unaffected by a change in $\mathrm{pH}$ value of the medium. Of the fatty acids tested, those with the lowest minimum inhibitory concentrations were the poly-unsaturated acids, linoleic, linolenic and arachidonic acids. However, the minimum inhibitory concentration of linoleic acid, with two double bonds, was somewhat less than that of linolenic acid, with three double bonds. At pH 6.5 and 7.5 , the minimum inhibitory concentrations of methyl linoleate and methyl linolenate were greater than the corresponding minimum inhibitory concentrations of the free acids. An increase from $\mathrm{pH} 6.5$ to $\mathrm{pH} 7.5$ increased the minimum inhibitory concentrations of the methyl esters of linoleic and linolenic acids.

Comparison of the results given in Table 4 with those given in Table 2 shows that, of the major fatty acids present in the unesterified fatty acid fraction of the intestinal contents (sample no. 1), only linoleic and arachidonic acids occurred in the intestinal fluid at concentrations in excess of their respective minimum inhibitory concentrations. Thus it seemed reasonable to conclude that the inhibitory activity of the unesterified fatty acid fraction of the intestinal contents (sample no. 1) was due to linoleic and arachidonic acids.

\section{The inhibitory activity of pure phospholipids}

A number of pure phospholipids obtained from various sources were tested (in $0.1 \mathrm{M}$-phosphate buffer, $\mathrm{pH} 6.5$, containing $0.1 \%$, w/v, Tween 80 ) for antibacterial activity at concentrations which the phospholipids might be expected to attain in the intestinal fluid. Lecithin and phosphatidyl ethanolamine (from egg yolk) were inactive at concentrations as high as $10^{-3} \mathrm{M}$ (i.e. lecithin, $77 \mathrm{mg} . / 100 \mathrm{ml}$; phosphatidyl ethanolamine, $73 \mathrm{mg} . / 100 \mathrm{ml}$.). Sphingomyelin (Koch-Light Laboratories Ltd.) was also inactive at $10^{-3} \mathrm{M}(75 \mathrm{mg} . / 100 \mathrm{ml}$.). Lysolecithin, prepared from egg yolk lecithin, was active at $10^{-3} \mathrm{M}(51 \mathrm{mg} . / 100 \mathrm{ml}$.); dilution experiments showed that the minimum inhibitory concentration of lysolecithin was $0.9 \times 10^{-4} \mathrm{M}(4.5 \mathrm{mg} . / 100 \mathrm{ml}$.). Owing to the small amount of lysophosphatidyl ethanolamine available, the highest concentration at which this compound was tested was $2 \times 10^{-4} \mathrm{M}(9 \cdot 3 \mathrm{mg} . / 100 \mathrm{ml}$.). At this concentration, lysophosphatidyl ethanolamine was inactive. The concentration of lysophosphatidyl ethanolamine in the intestinal fluid of sample no. 1 (Table 3) was only $3.1 \mathrm{mg}$. $/ 100 \mathrm{ml}$. Phosphatidic acid (prepared from egg-yolk lecithin) and diphosphatidyl glycerol (prepared from pig heart) were not active at $10^{-3} \mathrm{M}$ (i.e. phosphatidic acid, $69 \mathrm{mg}$./100 ml.; diphosphatidyl glycerol, $143 \mathrm{mg} . / 100 \mathrm{ml}$.).

Comparison of these findings with the results given in Table 3 showed that in the intestinal fluid of sample no. 1 the concentration of lysolecithin was 7 times the minimum inhibitory concentration. The fact that phosphatidic acid and diphosphatidyl glycerol exhibited no antibacterial activity at concentrations far in excess of the concentration of component $A$ in the intestinal fluid (Table 3) would seem to indicate that component A was neither phosphatidic acid nor diphosphatidyl glycerol. 


\section{Experiments with biliary lecithin}

It seemed possible that the lysolecithin and the unesterified unsaturated fatty acids in the intestinal contents might have resulted in part from the action of the phospholipase A secreted in the pancreatic juice on the lecithin in the bile. Accordingly, a sample of pure lecithin, prepared from pig bile, was hydrolysed by the phospholipase A extracted from an acetone-dried powder of pig pancreas. The products of hydrolysis were separated by silicic acid chromatography and the compositions and the antibacterial activities of the original bile lecithin and the resulting lysolecithin and fatty acids were determined. The fatty acid composition of the bile lecithin and lysolecithin,

Table 5. Fatty acid compositions of biliary lecithin, the lysolecithin and fatty acids derived from the biliary lecithin, and the lysolecithin isolated from pig intestinal contents (sample no. 1)

Sample no. 1 was from a pool from 4 pigs having had food withheld for $24 \mathrm{hr}$ before slaughter.

$\begin{array}{cccc}\text { Lecithin } & \begin{array}{c}\text { Lysolecithin } \\ \text { from bile } \\ \text { from bile }\end{array} & \begin{array}{c}\text { Fatty acids } \\ \text { lecithin } \beta \text {-position }\end{array} & \begin{array}{c}\text { Lysolecithin } \\ \text { of bile lecithin intestinal }\end{array} \\ \text { contents }\end{array}$

Fatty acid

Myristic (14:0)
Pentadecylic (15:0)
Palmitic (16:0)
Palmitoleic (16:1)
$-\quad(17: 0 \mathrm{br})$
Margaric (17:0)
Stearic (18:0)
Oleic (18:1)
Linoleic (18:2)
Linolenic (18:3)
Arachidonic (20:4)

Fatty acid composition (\%)

with the composition of the fatty acids derived from the $\beta$-position of the lecithin, are shown in Table 5. The fatty acid composition of the lysolecithin isolated from the intestinal contents (sample no. 1) is also given in Table 5. The similarity in fatty acid composition of the two samples of lysolecithin shown in Table 5 should be noted.

The bile lecithin was inactive at the highest concentration tested $(50 \mathrm{mg} . / 100 \mathrm{ml}$.). The lysolecithin derived from the bile lecithin was active at the highest concentration tested (33 mg./100 ml.) and dilution experiments showed that, in $0.1 \mathrm{M}$-phosphate buffer ( $\mathrm{pH} 6.5)$ and in the presence of $0.1 \%(\mathrm{w} / \mathrm{v})$ Tween 80 , the minimum inhibitory concentration of lysolecithin from this source was between 6.6 and $2.7 \mathrm{mg} . / 100 \mathrm{ml}$. This compares quite well with the minimum inhibitory concentration found for the lysolecithin prepared from egg yolk lecithin (i.e. $4.5 \mathrm{mg} . / 100 \mathrm{ml}$.). Since lysolecithin is to some extent water soluble, tests were also made with the lysolecithin derived from biliary lecithin, in $0 \cdot 1 \mathrm{M}$-phosphate buffer ( $\mathrm{pH} \mathrm{6.5)}$ but containing no Tween 80 . In the absence of Tween 80 , the minimum inhibitory concentration of lysolecithin was between 1.3 and $0.3 \mathrm{mg} . / 100 \mathrm{ml}$. Thus the presence of Tween 80 appeared to increase the minimum inhibitory concentration of lysolecithin.

The unesterified fatty acids derived from the $\beta$-position of the biliary lecithin were 
active and the minimum inhibitory concentration was between 18.2 and $7 \cdot 3 \mathrm{mg}$. total fatty acid $/ 100 \mathrm{ml}$. The calculated concentrations of the individual fatty acids corresponding to these two concentrations of total fatty acids in the test solutions are given in Table 6. It may be seen that the antibacterial activity of the total fatty acids at a concentration of $18.2 \mathrm{mg} . / 100 \mathrm{ml}$. could well be accounted for by the fact that the minimum inhibitory concentration of linoleic acid (i.e. $5 \cdot 6 \mathrm{mg} . / 100 \mathrm{ml}$.) was exceeded. The minimum inhibitory concentration of linoleic acid was not exceeded in the test solution containing $7 \cdot 3 \mathrm{mg}$. total fatty acids $/ 100 \mathrm{ml}$. The minimum inhibitory concentration of arachidonic acid (i.e. $6.1 \mathrm{mg} . / 100 \mathrm{ml}$.) was not exceeded in the test solutions containing either 18.2 or $7 \cdot 3 \mathrm{mg}$. of total fatty acid/100 ml.

Table 6. The concentration of individual fatty acids in a sample inhibitory for Clostridium welchii NCTC 8246 (containing $18.2 \mathrm{mg}$. total fatty acid/100 ml.) and a non-inhibitory sample (containing $7.3 \mathrm{mg}$. total fatty acid/100 ml.) derived from the $\beta$-position of biliary lecithin by the action of pig pancreatic phospholipase $A$

\begin{tabular}{|c|c|}
\hline \multicolumn{2}{|c|}{ Total fatty acids $(\mathrm{mg} . / 100 \mathrm{ml})}$. \\
\hline $18 \cdot 2$ & $7 \cdot 3$ \\
\hline \multicolumn{2}{|c|}{ Individual fatty acids (mg./100 ml. } \\
\hline 0.07 & 0.03 \\
\hline 0.04 & 0.01 \\
\hline 1.08 & 0.43 \\
\hline 0.22 & 0.09 \\
\hline 0.09 & 0.04 \\
\hline 0.05 & 0.02 \\
\hline 0.67 & 0.27 \\
\hline $5 \cdot 56$ & $2 \cdot 23$ \\
\hline 6.98 & 2.80 \\
\hline 0.42 & 0.17 \\
\hline $2 \cdot 72$ & 1.09 \\
\hline
\end{tabular}

Experiments with samples of intestinal contents of differing inhibitory activities

An attempt was made to correlate the different inhibitory activities of various samples of intestinal contents with the concentrations of inhibitory factors present in each sample. Three samples of intestinal contents were chosen for this investigation. Pooled sample no. 2 (high inhibitory activity) was obtained from 4 pigs from which food had been withheld for $24 \mathrm{hr}$ before slaughter; the inhibitory activity of sample no. 2 was retained even after a 25 -fold dilution of the intestinal contents. Pooled sample no. 3 (medium inhibitory activity) was obtained from four pigs from which food had been withheld for $21 \mathrm{hr}$ before slaughter; the inhibitory activity of sample no. 3 was lost after a 2 -fold dilution of the intestinal contents. Sample no. 4 possessed no antibacterial activity and was obtained from one pig killed $4 \mathrm{hr}$ after being given food; inhibitory activity was detected in sample no. 4 after a $2 \cdot 5$-fold concentration of the intestinal contents.

The lipid compositions of the three samples of intestinal contents are shown in Table 7. It may be seen that the total lipid content of the dry material was greatest in the sample with high antibacterial activity and lowest in the sample with no antibacterial activity. In the sample of high antibacterial activity the unesterified fatty acid content was about 5 times greater than that of the sample with no antibacterial 
activity. The proportion of lysolecithin in the total phospholipids of the sample with high activity was considerably greater than in the phospholipids of the samples with medium or no activity.

\section{Table 7. Lipid compositions of samples of pig intestinal contents with different inhibitory activities against Clostridium welchii NCTC 8246}

\begin{tabular}{|c|c|c|c|}
\hline & $\begin{array}{l}\text { Sample no. } 2^{*} \\
\text { (high activity) }\end{array}$ & $\begin{array}{c}\text { Sample no. } 3 \dagger \\
\text { (medium activity) }\end{array}$ & $\begin{array}{c}\text { Sample no. } 4 \ddagger \\
\text { (no activity) }\end{array}$ \\
\hline & \multicolumn{3}{|c|}{ Lipid composition (g./100 g. dry material) } \\
\hline Total lipid & $10 \cdot 8$ & $7 \cdot 70$ & 3.03 \\
\hline Neutral lipid & $3 \cdot 81$ & $3 \cdot 63$ & $1 \cdot 33$ \\
\hline Unesterified fatty acids & $6 \cdot 10$ & $3 \cdot 41$ & $1 \cdot 25$ \\
\hline \multirow[t]{2}{*}{ Total phospholipids } & 0.893 & 0.665 & 0.448 \\
\hline & \multicolumn{3}{|c|}{ Phospholipid composition (g./100 g. total phospholipid } \\
\hline Component A & $25 \cdot 9$ & $27 \cdot 3$ & $27 \cdot 7$ \\
\hline Phosphatidyl ethanolamine & $18 \cdot 5$ & $19 \cdot 8$ & $22 \cdot 3$ \\
\hline Lysophosphatidyl ethanolamine & 6.6 & $7 \cdot 5$ & $2 \cdot 2$ \\
\hline Lecithin & $17 \cdot 0$ & $21 \cdot 0$ & $19 \cdot 2$ \\
\hline Sphingomyelin & $9 \cdot 0$ & $11 \cdot 0$ & $16 \cdot 4$ \\
\hline Lysolecithin & $23 \cdot 0$ & $13 \cdot 3$ & $12 \cdot 1$ \\
\hline
\end{tabular}

* Sample no. 2, a pool from 4 pigs having had food withheld for $24 \mathrm{hr}$ before slaughter.

$\dagger$ Sample no. 3, a pool from 4 pigs having had food withheld for $21 \mathrm{hr}$ before slaughter.

\$ Sample no. 4 , obtained from one pig killed $4 \mathrm{hr}$ after being given food.

Table 8. Compositions of the unesterified fatty acids and concentrations of each unesterified fatty acid in the fluid phase of pig intestinal contents of different inhibitory activities against Clostridium welchii NCTC 8246

Fatty acid

Myristic (14:0)

Pentadecylic (15:0)

Palmitoleic (16:1)

Palmitic (16:0) - (17:0 br)

Margaric (17:0)

Stearic (18:0)

Oleic (18:1)

Linoleic (18:2)

Linolenic (18:3)

Arachidonic (20:4)

Total

\begin{tabular}{|c|c|}
\hline \multicolumn{2}{|c|}{$\begin{array}{l}\text { Sample no. } 2 \\
\text { (high activity) }\end{array}$} \\
\hline \multicolumn{2}{|c|}{$\begin{array}{l}\text { Fatty acid } \\
\text { in intestinal fluid }\end{array}$} \\
\hline & (mg. $/ 100 \mathrm{ml}$ \\
\hline $0 \cdot 6$ & $\begin{array}{l}2 \cdot 2 \\
1 \cdot 1\end{array}$ \\
\hline $\begin{array}{l}0.3 \\
1.9\end{array}$ & $\begin{array}{l}1.1 \\
7 \cdot 0\end{array}$ \\
\hline $20 \cdot 4$ & 75.5 \\
\hline 0.5 & 1.9 \\
\hline 1.4 & $5 \cdot 2$ \\
\hline $15 \cdot 4$ & 57.0 \\
\hline $21 \cdot 5$ & $79 \cdot 5$ \\
\hline 28.6 & 106.0 \\
\hline $2 \cdot 0$ & $7 \cdot 4$ \\
\hline \multirow[t]{2}{*}{$6 \cdot 1$} & 22.6 \\
\hline & $370 \cdot 0$ \\
\hline
\end{tabular}

Sample no. 3

(medium activity)

Fatty acid in intestinal fluid

$\%$ (mg./100 ml.)

0.6

0.7

1.7

$28 \cdot 4$

0.7

$1 \cdot 6$

$16 \cdot 3$

18.0

$26 \cdot 1$

$2 \cdot 4$

$2 \cdot 4$
Sample no. 4

(no activity)

Fatty acid

in intestinal fluid

$\% \quad$ (mg./100 ml.)

$0.7 \quad 0.5$

$1 \cdot 1 \quad 0.7$

$2 \cdot 3 \quad 1 \cdot 4$

$36 \cdot 3 \quad 23 \cdot 7$

$\begin{array}{ll}1 \cdot 1 & 0.7\end{array}$

$1.9 \quad 1 \cdot 2$

$12 \cdot 4 \quad 8 \cdot 1$

$32 \cdot 3 \quad 21 \cdot 1$

$8 \cdot 3 \quad 5 \cdot 4$

$1 \cdot 3 \quad 0 \cdot 9$

$1 \cdot 1 \quad 0 \cdot 7$

$65 \cdot 2$

The compositions of the unesterified fatty acids obtained from the samples of intestinal contents are given in Table 8 , together with the calculated concentrations of the individual fatty acids in the intestinal fluid. In the sample of high activity (no. 2) the concentrations of linoleic and arachidonic acids in the intestinal fluid exceeded the respective minimum inhibitory concentrations of these two fatty acids (see Table 4). 
In the sample of medium activity (no. 3) the concentration of linoleic acid in the intestinal fluid exceeded the minimum inhibitory concentration of this fatty acid. The respective minimum inhibitory concentrations were not exceeded either by the concentrations of linoleic or arachidonic acids in the intestinal fluid of the sample with no antibacterial activity. Dilution experiments with the total unesterified fatty acid fraction obtained from sample no. 2 showed that activity was lost when the concentration of unesterified fatty acids was reduced from $23 \cdot 1$ to $11.5 \mathrm{mg} . / 100 \mathrm{ml}$. (Table 9). This decrease in concentration of total unesterified fatty acids corresponded

Table 9. Effects of concentration of the unesterified fatty acid fractions, obtained from pig intestinal contents of different activities, on the inhibitory activities against Clostridium welchii NCTC 8246

\begin{tabular}{|c|c|c|c|c|}
\hline & \multirow{2}{*}{$\begin{array}{l}\text { Concentration of } \\
\text { total unesterified } \\
\text { fatty acids } \\
(\mathrm{mg} . / 100 \mathrm{ml} \text {.) }\end{array}$} & \multirow[b]{2}{*}{$\begin{array}{l}\text { Recorded } \\
\text { antibacterial } \\
\text { activity }\end{array}$} & \multicolumn{2}{|c|}{$\begin{array}{l}\text { Calculated concentrations } \\
\text { (mg./100 ml.) }\end{array}$} \\
\hline & & & $\begin{array}{c}\text { Linoleic } \\
\text { acid }\end{array}$ & $\begin{array}{l}\text { Arachidonic } \\
\text { acid }\end{array}$ \\
\hline Sample no. 2 (high activity) & $\begin{array}{l}370 \\
185 \\
92 \cdot 5 \\
46 \cdot 2 \\
23 \cdot 1 \\
11 \cdot 5\end{array}$ & $\begin{array}{l}+ \\
+ \\
+ \\
+ \\
+ \\
-\end{array}$ & $\begin{array}{c}106^{*} \\
53^{*} \\
26 \cdot 5^{*} \\
13 \cdot 2^{*} \\
6 \cdot 6^{*} \\
3 \cdot 3\end{array}$ & $\begin{array}{c}22.6^{*} \\
11 \cdot 3^{*} \\
5.6 \\
2.8 \\
1.4 \\
0.7\end{array}$ \\
\hline Sample no. 3 (medium activity) & $\begin{array}{r}175 \\
87 \cdot 5 \\
43.7 \\
21 \cdot 8 \\
10.9 \\
5.4\end{array}$ & $\begin{array}{l}+ \\
+ \\
+ \\
- \\
- \\
-\end{array}$ & $\begin{array}{c}45 \cdot 7^{*} \\
22 \cdot 8^{*} \\
11 \cdot 4^{*} \\
5 \cdot 6 \\
2 \cdot 8 \\
1 \cdot 4\end{array}$ & $\begin{array}{l}4 \cdot 2 \\
2 \cdot 1 \\
1 \cdot 1 \\
0 \cdot 6 \\
0 \cdot 3 \\
0 \cdot 1\end{array}$ \\
\hline Sample no. 4 (no activity) & $\begin{array}{l}65 \cdot 2 \\
81 \cdot 5 \\
163 \\
326\end{array}$ & $\begin{array}{l}- \\
\overline{+} \\
+\end{array}$ & $\begin{array}{c}5 \cdot 4 \\
6 \cdot 8^{*} \\
13 \cdot 5^{*} \\
27 \cdot 1^{*}\end{array}$ & $\begin{array}{l}0.7 \\
0.9 \\
1 \cdot 8 \\
3.6\end{array}$ \\
\hline
\end{tabular}

to a decrease in concentration of linoleic acid from 6.6 to $3.3 \mathrm{mg} . / 100 \mathrm{ml}$. Part of the antibacterial activity of the unesterified fatty acids at concentrations above $92 \mathrm{mg}$./ $100 \mathrm{ml}$. would be due to arachidonic acid. Dilution of the unesterified fatty acid fraction obtained from sample no. 3 resulted in the loss of inhibitory activity when the concentration of unesterified fatty acids was decreased from 43.7 to $21.8 \mathrm{mg}$.) $100 \mathrm{ml}$, i.e. a decrease in the concentration of linoleic acid from 11.4 to $5.7 \mathrm{mg} . / 100 \mathrm{ml}$. As expected, the total unesterified fatty acids obtained from sample no. 4 were not active when tested at the concentration at which they occurred in the intestinal fluid $(65.2 \mathrm{mg} . / 100 \mathrm{ml}$.). However, antibacterial activity was observed when the concentration of total unesterified fatty acids was increased to $163 \mathrm{mg} . / 100 \mathrm{ml}$. At this concentration of total unesterified fatty acids the minimum inhibitory concentration of linoleic acid was exceeded. The calculated concentrations of the individual phospholipids in the intestinal fluid of the three samples are given in Table 10. The minimum inhibitory concentration of lysolecithin was considerably less than the concentration of lysolecithin in the intestinal fluid of the sample with high activity, but was about 
the same as the concentration of lysolecithin in the intestinal fluid of the sample with medium activity. The concentration of lysolecithin in the intestinal fluid of the sample with no antibacterial activity was below the minimum inhibitory concentration of lysolecithin. The results of dilution experiments (Table 11) show that antibacterial activity was retained when the concentration of the total phospholipids obtained from sample no. 2 was reduced to $13.5 \mathrm{mg} / 100 \mathrm{ml}$. At this concentration of total phospholipids, the calculated concentration of lysolecithin was somewhat below the minimum inhibitory concentration of lysolecithin. However, the unidentified phospholipid would also contribute to the inhibitory activity of the total phospholipid fraction. Experiments with sample no. 3 showed that the loss of inhibitory activity that was observed on diluting the total phospholipids to $17.0 \mathrm{mg} . / 100 \mathrm{ml}$. corresponded with a decrease in the calculated concentration of lysolecithin to $2.3 \mathrm{mg} . / 100 \mathrm{ml}$. When the concentration of the total phospholipids obtained from sample no. 4 was increased, antibacterial activity was observed at $58.5 \mathrm{mg} . / 100 \mathrm{ml}$. At this concentration of total phospholipids the calculated concentration of lysolecithin was greater than the minimum inhibitory concentration of lysolecithin.

Table 10. Concentrations of individual phospholipids in the fluid phase of pig intestinal contents of different inhibitory activities against Clostridium welchii NCTC 8246

\begin{tabular}{lrcr} 
& $\begin{array}{c}\text { Sample no. 2 } \\
\text { (high activity) } \\
\text { Concentration (mg./100 ml.) }\end{array}$ & $\begin{array}{c}\text { Sample no. 3 } \\
\text { (medium activity) }\end{array}$ & $\begin{array}{c}\text { Sample no. 4 } \\
\text { (no activity) }\end{array}$ \\
\cline { 2 - 4 } Total phospholipids & $54 \cdot 2$ & $34 \cdot 1$ & $23 \cdot 4$ \\
Component A & $14 \cdot 0$ & $9 \cdot 3$ & $6 \cdot 5$ \\
Pnosphatidyl ethanolamine & $10 \cdot 0$ & $6 \cdot 8$ & $5 \cdot 2$ \\
Lysophosphatidyl ethanolamine & $3 \cdot 6$ & $2 \cdot 6$ & $0 \cdot 5$ \\
Lecithin & $9 \cdot 2$ & $7 \cdot 2$ & $4 \cdot 5$ \\
Sphingomyelin & $4 \cdot 9$ & $3 \cdot 8$ & $3 \cdot 8$ \\
Lysolecithin & $12 \cdot 5$ & $4 \cdot 5$ & $2 \cdot 8$
\end{tabular}

Table 11. Effect of concentration of phospholipids from pig intestinal samples 2, 3 and 4 on their inhibitory activities against Clostridium welchii NCTC 8246

\begin{tabular}{|c|c|c|c|}
\hline & $\begin{array}{l}\text { Concentration of } \\
\text { total phospholipids } \\
(\mathrm{mg} . / 100 \mathrm{ml} .)\end{array}$ & $\begin{array}{l}\text { Recorded } \\
\text { antibacterial } \\
\text { activity }\end{array}$ & $\begin{array}{l}\text { Calculated } \\
\text { concentration of } \\
\text { lysolecithin } \\
(\mathrm{mg} . / 100 \mathrm{ml} .)\end{array}$ \\
\hline Sample no. 2 (high activity) & $\begin{array}{r}54.2 \\
27.1 \\
13.5 \\
6.7 \\
3.3 \\
1.6\end{array}$ & $\begin{array}{l}+ \\
+ \\
+ \\
- \\
- \\
-\end{array}$ & $\begin{array}{r}12.5 \\
6 \cdot 3 \\
3 \cdot 1 \\
1.6 \\
0.8 \\
0.4\end{array}$ \\
\hline Sample no. 3 (medium activity) & $\begin{array}{r}34 \cdot 1 \\
17 \cdot 0 \\
8 \cdot 5\end{array}$ & $\begin{array}{l}+ \\
-\end{array}$ & $\begin{array}{l}4 \cdot 5 \\
2 \cdot 3 \\
1 \cdot 1\end{array}$ \\
\hline Sample no. 4 (no activity) & $\begin{array}{r}23 \cdot 4 \\
29 \cdot 2 \\
58 \cdot 5 \\
117 \cdot 0\end{array}$ & $\begin{array}{l}- \\
- \\
+ \\
+\end{array}$ & $\begin{array}{r}2 \cdot 8 \\
3 \cdot 6 \\
7 \cdot 3 \\
14 \cdot 7\end{array}$ \\
\hline
\end{tabular}




\section{The fatty acid composition of the lipids isolated from \\ Clostridium welchii NCTC 8246}

In view of the inhibitory action of linoleic, linolenic and arachidonic acids on the growth of Clostridium welchii NCTC 8246 it was of interest to determine the composition of the fatty acids synthesized by this organism when grown in a fat-free medium. C. welchii, NCTC 8246, was therefore grown in the defined medium of Boyd, Logan \& Tytell (1948). The organisms were harvested by centrifugation, washed twice with $0.85 \%(\mathrm{w} / \mathrm{v})$ sodium chloride solution and freeze-dried. The lipids were extracted from the organisms and the composition of the constituent fatty acids determined. The fatty acids listed in Table 12 amounted to about $94 \%$ of those present. The remaining $6 \%$ was accounted for by small amounts of several unidentified acids. The results in Table 12 show that saturated acids comprised over $80 \%$ of the fatty acids of $C$. welchii. An octadecadienoic acid was present in very low concentration (0.6\%) but we have no evidence that this fatty acid was linoleic acid, i.e. $\Delta^{9,12}$ octadecadienoic acid. Oxidative degradation studies were not possible on the small amounts of octadecadienoic acid that could be isolated from the lipids obtained from the organism.

Table 12. Composition of total fatty acids obtained from Clostridium welchii, type A, NCTC 8246

\begin{tabular}{lrcr}
\multicolumn{1}{c}{ Fatty acid } & $\%$ & Fatty acid & $\%$ \\
Lauric (12:0) & $21 \cdot 4$ & Linoleic $(18: 2)$ & $0 \cdot 6$ \\
Myristic (14:0) & $18 \cdot 6$ & $-(19: 1)$ & $1 \cdot 3$ \\
Palmitic (16:0) & $12 \cdot 6$ & Arachidic $(20: 0)$ & $14 \cdot 2$ \\
Palmitoleic (16:1) & $1 \cdot 3$ & $-\quad(20: 1)$ & $2 \cdot 6$ \\
Stearic (18:0) & $14 \cdot 8$ & $-\quad(21: 1)$ & $2 \cdot 9$ \\
Oleic (18:1) & $3 \cdot 3$ & &
\end{tabular}

\section{DISCUSSION}

The results of the work now reported indicate that the antibacterial activity of the contents of the small intestine of pigs may be attributed to the presence of unesterified fatty acids, lysolecithin and an unidentified phospholipid. It has been well established that unsaturated fatty acids exert an antibacterial influence on Gram-positive microorganisms. The subject was reviewed by Nieman (1954), who concluded that the inhibitory effects of unsaturated fatty acids increased as the number of double bonds in the molecule increased. Our findings (Table 4) support this conclusion in that the inhibitory effect of linoleic acid (18:2) was far greater than that of oleic acid (18:1). However, the minimum inhibitory concentration of arachidonic acid (20:4) was about the same as that of linoleic acid, whereas the minimum inhibitory concentration of linolenic acid (18:3) was somewhat greater than that of linoleic acid (Table 4). The mechanism of the antibacterial effect of unsaturated fatty acids has yet to be elucidated. As suggested by Kodicek \& Worden (1945) the unsaturated fatty acids could form an adsorption layer around the bacterium and inhibit the absorption of essential nutrients. On the other hand, the unsaturated fatty acids might enter the bacterial cell and inhibit some essential metabolic process. In this respect it should be noted that unsaturated fatty acids do not appear to be synthesized to any extent by Clostridium welchii (Table 12). The results in Table 12 are in fair agreement with those of MacFarlane 
(1962), who found that the fatty acids of $C$. welchii type A grown in a medium containing $3.0 \%$ peptone, $0.5 \%$ glucose and $0.45 \%$ sodium chloride were predominantly saturated and consisted mainly of lauric (12:0) and arachidic (20:0) acids.

Lysolecithin has been isolated from the contents of the small intestine of man (Borgström, 1957) and of sheep (Lennox, Lough \& Garton, 1965). Hoffman (1961) and Lennox et al. (1965) suggested that lysolecithin, in addition to bile acids, facilitates the absorption of fat by forming soluble micelles with fatty acids and $\beta$-monoglycerides in the intestinal lumen. As far as we are aware, the only previous report drawing attention to the antibacterial properties of lysolecithin is that of Trager (1948), who found that the growth of Lactobacillus casei in a medium that contained suboptimal amounts of biotin was prevented by the presence of low concentrations of lysolecithin. At present it is difficult to put forward any suggestion about the nature or origin of the unidentified phospholipid component $\mathrm{A}$ that we found to inhibit the growth of Clostridium welchii.

It seems reasonable to contend that the lysolecithin present in the contents of the small intestine is derived from the hydrolytic cleavage of lecithin secreted in the bile. This view is supported by the similarity between the fatty acid composition of the lysolecithin isolated from the intestinal contents and that of the lysolecithin prepared from the lecithin isolated from pig bile (Table 5). The biliary lecithin is presumably hydrolysed in the lumen of the small intestine by the action of the phospholipase A which is secreted by the pancreas. The results in Table 5 show that the fatty acids liberated from the $\beta$-position of the biliary lecithin by phospholipase $\mathrm{A}$ were particularly rich in linoleic acid. This liberation of linoleic acid from the $\beta$-position of the biliary lecithin could account for the relatively high concentrations of linoleic acid observed in the unesterified fatty acid fraction of the contents of the small intestine of pigs which had not received any food for 20-24 hr. However, the fatty acids liberated from the $\alpha$ and $\alpha^{\prime}$ positions of dietary or endogenous triglycerides by the hydrolytic action of pancreatic lipase might also contribute to the unesterified fatty acid fraction of the contents of the small intestine. Inhibitory activity was thus absent from the contents of the stomach, caecum and large intestine since little or no hydrolysis of lipids occurs in the stomach and most of the products of lipolysis are absorbed before the digesta reaches the caecum. Bernhart et al. (1952) showed that the inclusion of soya lecithin in the diet of rats decreased the numbers of Clostridium welchii in the faeces.

It is not clear why the concentration of inhibitory lipids in the contents of the small intestine increases as the time after feeding increases. Moore (1952) showed that the rate of passage of digesta from the stomach to the small intestine of the pig decreased very markedly between 4 and $6 \mathrm{hr}$ after feeding. If there were no such decrease in the rate of secretion of bile during this period then there would be an increase in the concentrations of lipids of biliary origin in the fluid phase of the intestinal contents. This might explain why inhibitory activity is first detected in the contents of the small intestine $6 \mathrm{hr}$ after feeding. Consistent with our findings are those of Smith (1961), who observed that it was possible to increase the numbers of Clostridium welchii in the intestinal contents of pigs by inducing the animals to consume large quantities of food after a period of enforced starvation. Subsequent periods of starvation resulted in a rapid decrease in the counts of $C$. welchii in the intestinal contents. Our results show that even under the conditions of normal feeding practice 
there is a period during each day when the contents of the small intestine are inhibitory for $C$. welchii. It is thus tempting to suggest that the production of inhibitory lipids in the contents of the small intestine constitutes a mechanism whereby the numbers of C. welchii type A, the normal type in the alimentary tract of the pig, are controlled.

The authors thank Dr R. Braude of the Pig Husbandry Department for his cooperation and Miss J. A. Hannaford and Miss J. Carrinci for their skilled technical assistance.

\section{REFERENCES}

Albrink, M. J. (1959). The microtitration of total fatty acids of serum with notes on the estimation of triglycerides. J. Lipid Res. 1, 53.

AlLEN, R. J. L. (1940). The estimation of phosphorus. Biochem. J. 34, 858.

Bernhart, F. W., Durbin, G. T., Linden, E., Hassinen, J. B. \& Tomarelli, R. M. (1952). Effect of soya 'lecithin' on number of clostridia in rat faeces. Proc. Soc. exp. Biol. Med. 79, 470.

Bier, M. (1955). In Methods in Enzymology. Ed. by S. P. Colowick and N. O. Kaplan. Vol. 1, p. 631. New York: Academic Press Inc.

BORGSTRöM, B. (1957). Studies of the phospholipids of human bile and small intestinal contents. Acta chem. scand. 11, 749.

Boyd, M. J., LogaN, M. A. \& Tytell, A. A. (1948). The growth requirements of Clostridium perfringens (welchii) вР6к. J. biol. Chem. 174, 1013.

CARroll, K. K. (1961). Separation of lipid classes by chromatography on florisil. J. lipid Res. $2,135$.

Chen, P. S., Torribara, T. Y. \& Warner, H. (1956). Microdetermination of phosphorus. Analyt. Chem. 28, 1756.

ELLNER, D. D. (1956). A medium promoting rapid quantitative sporulation in Clostridium perfringens. J. Bact. 71, 495.

Farquhar, J. W., Insull, W., Rowen, P., Stoffel, W. \& Ahrens, E. H. (1959). The analysis of fatty acid mixtures by gas-liquid chromatography. Nutr. Rev. 17. Suppl. no 8, pt 2 .

Folch, J., LeEs, M. \& STANLEY, G. H. S. (1957). A simple method for the isolation and purification of total lipids from animal tissues. J. biol. Chem. 226, 497.

Fuller, R., Newland, L. G. M., Briggs, C. A. E., Braude, R. \& Mitchell, K. G. (1960). The normal intestinal flora of the pig. IV. The effect of dietary supplements of penicillin, chlortetracycline or copper sulphate on the faecal flora. J. appl. Bact. 23, 195.

Hanahan, D. J., Dittmer, J. C. \& Warashina, E. (1957). A column chromatographic separation of classes of phospholipids. J. biol. Chem. 228, 685 .

Hofmann, A. F. (1961). In Enzymes of Lipid Metabolism. Ed. by P. Desnuelle, p. 158. London: Pergamon Press.

Horrocks, L. A. (1963). Thin-layer chromatography of brain phospholipids. J. Am. Oil Chem. Soc. 40, 235.

JAMES, A. T. (1959). Determination of the degree of unsaturation of long chain fatty acids by gasliquid chromatography. J. Chromatog. 2, 552.

KaTES, M. (1954). Lecithinase systems in sugar beet, spinach, cabbage and carrot. Can. J. Biochem. 32, 571.

KODICEK, E. \& WORDEN, A. N. (1945). The effect of unsaturated fatty acids on Lactobacillus helveticus and other gram-positive micro-organisms. Biochem. J. 39, 78.

LAws, B. M. \& MOORE, J. H. (1963). The lipase and esterase activities of the pancreas and small intestine of the chick. Biochem. J. 87, 632 .

Lennox, A. M., Lough, A. K. \& Garton, G. A. (1965). The effect of bile on the composition of digesta in the small intestine of the sheep. Biochem. J. 96, $27 \mathrm{P}$.

LoNG, C. \& PENNY, I. F. (1957). The structure of the naturally occurring phosphoglycerides. 3. Action of moccasin-venom phospholipase A on ovolecithin and related substances. Biochem. J. $65,382$.

MacFarlane, M. G. (1961). Cardiolipin and other phospholipids in ox liver. Biochem. J. 78, 44.

MACFARLANe, M. G. (1962). Characterization of lipoamino-acids as o-amino-acid esters of phosphatidyl-glycerol. Nature, Lond. 196, 136

Magee, L., Gallai-Hatchard, J., Sanders, H. \& Thompson, R. H. S. (1962). The purification and properties of phospholipase A from human pancreas. Biochem. J. 83, 17.

MaNgold, H. K. (1961). Thin-layer chromatography of lipids. J. Am. Oil Chem. Soc. 38, 708.

MarinetT, G. V. (1963). Chromatographic separation, identification and analysis of phosphatides. J. Lipid Res. 3, 1. 
MarinetTi, G. V., ERbland, J. \& Kochen, J. (1957). Quantitative chromatography of phosphatides. Fedn Proc. Fedn Am. Socs exp. Biol. 16, 837.

MoORE, J. H. (1952). The Absorption and Excretion of Minerals by Pigs. PhD Thesis, University of Reading.

MOORE, J. H. \& Doran, B. M. (1961). Vitamin $\mathrm{B}_{12}$ and lipid metabolism in the chick embryo. Biochim. biophys. Acta 49, 617 .

MOORE, J. H. \& DORAN, B. M. (1962). Lipid metabolism in the normal and vitamin $B_{12}$-deficient chick embryo. Biochem. J. 84, 506.

MoORE, J. H. \& Williams, D. L. (1963). The influence of dietary fat on the liver lipids of the rabbit. Can. J. Biochem. 41, 1821.

MoOre, J. H. \& Williams, D. L. (1964). Some observations on the specificity of phospholipase A. Biochim. biophys. Acta 84, 41.

MOORE, J. H. \& WiLliams, D. L. (1965). Studies on the composition and structure of the phosphatidylcholine, phosphatidylethanolamine and triglyceride isolated from rabbit liver. Biochim. biophys. Acta $\mathbf{9 8}, 137$.

MORRIS, L. J. (1962). Separation of higher fatty acid isomers and vinylogues by thin layer chromatography. Chem. \& Ind. p. 1238.

Nelson, G. J. \& FreEman, N. K. (1959). Serum phospholipid analysis by chromatography and infrared spectrophotometry. J. biol. Chem. 234, 1375.

NIEMAN, C. (1954). Influence of trace amounts of fatty acids on the growth of microorganisms. Bact. Rev. 18, 147.

RHODEs, D. N. \& LEA, C. H. (1957). Phospholipids. 4. On the composition of hen's egg phospholipids. Biochem. J. 65, 526 .

SAUNDERS, L. (1957). Some properties of mixed sols of lecithin and lysolecithin. J. Pharm. Pharmacol. 9, 834.

SkIPSKI, V. P., Peterson, R. F. \& Barclay, M. (1964). Quantitative analysis of phospholipids by thin-layer chromatography. Biochem. J. 90, 374.

SмIтH, H. W. (1961). The development of the bacterial flora of the faeces of animals and man: the changes that occur during ageing. J. appl. Bact. 24, 235.

Stoffel, W., Chu, F. \& Ahrens, E. H. (1959). Analysis of long-chain fatty acids by gas-liquid chromatography. Micromethod for preparation of methyl esters. Analyt. Chem. 31, 307.

Trager, W. (1948). The effects of lysolecithin on the growth of Lactobacillus casei in relation to biotin, pantothenic acid, and fat-soluble material with biotin activity. J. Bact. 56, 195. 